\section{Intrusive thoughts of intentional harm to infants}

Lawrence et al have written about intrusive and unwanted thoughts of intentional harm to infants in the context of maternal postnatal depression, anxiety, and obsessive compulsive disorder (OCD). ${ }^{1}$ We know that these thoughts are common in new parents, not only affecting almost $50 \%$ of mothers, but also fathers. Their advice to health professionals is to normalise these thoughts for concerned parents with reassurance and to understand that by themselves the thoughts signify nothing sinister. The thoughts become significant when they interfere with the ability to live a normal life because the level of distress is so high, linked to the personal meaning of having the thought, rather than the specific content. These parents have no intention of harming their child. This is very different from a 'delusion', when a mother with psychosis or depression absolutely believes that her thoughts are real.

However, in the list of possible intrusive thoughts given, they do not include common examples of the most violent and repugnant thoughts that parents can experience, such as sexual abuse and cutting with knives. As a result, parents make elaborate plans to ensure these things cannot happen by avoiding changing nappies and refusing to cook, respectively. Not surprisingly, comorbidities with anxiety and depression are common. Parents are extremely unlikely to disclose these thoughts spontaneously because they are afraid that social services will be informed, and the child removed.

But health professionals are not used to hearing such awful thoughts expressed; a knee-jerk referral to social services is very possible. Within the context of perinatal OCD or depression and anxiety this would compound the damage and feed into the parents' worst fears.

GPs need to understand the condition of perinatal OCD and make the right diagnosis so that the optimum treatment is offered and social services are not involved. ${ }^{3}$ The treatment of choice is psychological cognitive behavioural therapy (CBT) with exposure and response prevention treatment (ERP). For more information, visit https://maternalocd.org/.
Judy Shakespeare,

GP, Oxford.

Email: judy.shakespearedvirginmedia.com

Fiona Challacombe,

Research Clinical Psychologist, Section of Women's Mental Health, Health Service and Population Research, King's College London, London.

Maria Bavetta,

Co-founder, Maternal OCD, Herts

\section{REFERENCES}

1. Lawrence PJ, Craske MG, Kempton C, et al. Intrusive thoughts and images of intentional harm to infants in the context of maternal postnatal depression, anxiety, and OCD. Br J Gen Pract 2017; DOI: https://doi.org/10.3399/bjgp17X692105.

2. Fairbrother N, Woody SR. New mothers' thoughts of harm related to the newborn. Arch Women's Ment Health 2008; 11(3): 221-229.

3. Challacombe F. Wroe AL. A hidden problem: consequences of the misdiagnosis of perinatal obsessive-compulsive disorder. Br J Gen Pract 2013; DOI: https://doi.org/10.3399/bjgp13X667376.

DOI: https://doi.org/10.3399/bjgp18X695393

\section{PsyScan e-tool to support diagnosis and management of psychological problems in general practice}

We read with great interest the article by Gidding et al about the effects of the e-tool PsyScan on patients with psychological problems in general practice. 'We agree that a tool is needed that can support management of these patients and we appreciate the effort in developing the PsyScan e-tool. However, we would like to discuss a few issues.

First, we approve of the randomisation method the authors used; however, patients were randomised before signing the detailed informed consent. We wonder if the initial assignment of patients in the intervention or control group may have influenced the decision to participate in the study. Was the number of participants who were excluded because they were not willing to sign the detailed consent similar in the intervention and control group? Participants who were assigned to the control group might be more likely to withdraw consent, because they could feel that participation had fewer benefits.

Second, participants in the intervention group first had to complete the threequestion distress screener. The score of this questionnaire was crucial for the advice and treatment the patients received. The validation of the three-question distress screener was investigated by Braam et $a l_{1}^{2}$ although this was evaluated in a population of employees and not in the general practice population. What were the authors' considerations for specifically choosing this questionnaire?

Third, the aim of the e-tool was to achieve more appropriate management of patients with psychological problems and provide an improvement of symptoms. The PsyScan resulted in a significant reduction of patientreported symptoms, although the number of the different GPs' actions were quite similar in both groups, and most of the differences were not significant. In our opinion, these small differences may not be clinically relevant. Our question is: did the authors consider another working mechanism that can explain the shown symptom reduction after 12 months?

Fourth, we wonder if the authors could explain why, after 3 and 6 months, there were no significant differences, whereas after 12 months' follow-up the difference in effects was present. Do the authors plan a longer-term follow-up, for example, after 18 or 24 months?

In conclusion, the PsyScan is a relevant tool for the GP and results in a better understanding between patient and doctor.

Rosalie van der Burg,

Associate Professor, Erasmus University Medical Center, Rotterdam.

Email: h.vanderburglerasmusmc.nl

Valerie Lardee,

Erasmus University Medical Center, Rotterdam.

Marieke Wouters,

Erasmus University Medical Center, Rotterdam.

Bart Koes,

Professor of General Practice, Erasmus University Medical Center, Rotterdam. 


\section{REFERENCES}

1. Gidding LG, Spigt M, Winkens B, et al. PsyScan e-tool to support diagnosis and management of psychological problems in general practice: a randomised controlled trial. Br J Gen Pract 2017; DOI: https://doi.org/10.3399/bjgp17X694109

2. Braam C, Van Oostrom SH, Terluin B, et al. Validation study of a distress screener. J Occup Rehabil 2009; 19(3): 231-237.

DOI: https://doi.org/10.3399/bjgp18X695405

\section{Author response}

Thank you for your letter and your interest in PsyScan. ${ }^{1}$ We are glad to answer your questions. The participants were randomised before they had to sign the detailed informed consent. This was very important to us because we did not want the research to cause any delay in treatment, especially in the case of the participants in the control group. The numbers of participants who were excluded because they did not sign the informed consent were similar for both groups. This information is already given in the article, and we described that we used block randomisation and that the included numbers of participants were similar for both groups.

Second, the three-question distress screener has no direct influence on the advice and treatment the participants received. The diagnostic and therapeutic advices were based on the 4-Dimensional Symptom Questionnaire that has been researched extensively in general practice.

Third, we agree that Table 1 is crucial to understand the probable working mechanism of PsyScan. This table combined with the significant reduction of patient-reported symptoms indicates that PsyScan's effect seems to be based on using more appropriate treatments for specific patients at specific times, resulting in better patient-treatment combinations.

Fourth, we ended the follow-up after 12 months. The presence of a statistically significant effect only after 12 months could indicate that PsyScan creates longerlasting effects as opposed to usual care. As you pointed out, PsyScan indeed seems to create a better understanding between patient and GP

\section{Luc G Gidding,}

Researcher, Department of Family Practice, Care and Public Health Research Institute, Maastricht University.

Email: luc.giddinglamaastrichtuniversity.nl

\section{REFERENCE}

1. Gidding LG, Spigt M, Winkens B, et al. PsyScan e-tool to support diagnosis and management of psychological problems in general practice: a randomised controlled trial. Br J Gen Pract 2017. DOI: https://doi.org/10.3399/bjgp17X694109.

DOI: https://doi.org/10.3399/bjgp18X695417

\section{Skill-mix change and the general practice workforce challenge}

The recent editorial on skill mix ('Skill mix change and the general practice workforce challenge')1 demonstrated a depressing recycling of familiar themes that have been around since at least the start of the century. ${ }^{2}$ Inevitably, there will be major challenges when attempting to configure a system where there are conflicting demands of efficiency (what gives value for money?), equity (what is a fair distribution of our limited resources?) and affordability (how much have we got to spend?); that needs to be both resilient and innovative; and is free at the point of entry.

The editorial concludes with a more useful challenge, that 'If changing skill-mix is the answer, what is the question?'I'd like to suggest two. First, Is current healthcare research a self-sustaining activity that has an imperceptible impact compared with the resources invested in it? Second, why has a historically determined mix of skills continued that seeks to force the NHS into the disciplinary matrix rather than the more logical converse?

A more useful approach may be to view the meaningless policy imperatives such as transformation, modernisation, sustainability, and skill mix as defensive devices - gestures designed to avoid the harsh realities of our situation with its challenges, ambiguities, and paradoxes. At least we can then be in a better position to start an honest debate about the best way forward.

David Kernick

GP, St Thomas Medical Group, Exeter.

Email: david.kernickanhs.net

\section{REFERENCES}

1. Nelson P, Martindale A-M, McBride A, et al. Skillmix change and the general practice workforce challenge. Br J Gen Pract 2018; DOI: https://doi. org/10.3399/bjgp18X694469.

2. Kernick D, Scott A. Economic approaches to doctor/ nurse skill mix. problems, pitfalls, and partial solutions. Br J Gen Pract 2001: 52(474): 42-46.

DOI: https://doi.org/10.3399/bjgp18X695429

\section{WAP plan}

I notice the plan starts with emollients etcetera before going on to topical steroids. I understand this complies with NICE guidelines and has been normal practice since the sixties.

However, I have not been able to find any evidence for their efficacy and it seems that they are more of a tradition than a useful treatment. Would children do just as well by starting treatment on the most appropriate topical steroid?

Gerald Michael,

Retired GP, London.

Email: gmm83abtinternet.com

\section{REFERENCE}

1. Powell K, Le Roux E, Banks JP, Ridd MJ. Developing a written action plan for children with eczema: a qualitative study. Br J Gen Pract 2018; DOI: https://doi.org/10.3399/bjgp17X693617.

DOI: https://doi.org/10.3399/bjgp18X695441

\section{Author response}

Dr Michael makes the very astute observation that, despite emollients forming the cornerstone of all guidelines and recommendations regarding the treatment of (atopic) eczema/dermatitis, the evidence base for their effectiveness is limited. He may be interested in the recently published Cochrane review by van Zureen and colleagues, which, although limited by the quality and relevance of published trials to NHS general practice, does provide some reassurance that moisturisation is effective. What there is even less certainty about is whether one emollient is clinically or more cost-effective than another, and linked to this the acceptability of different types of emollients (lotion, cream, gel, and ointment being the main ones) to patients and their carers. This is the subject of an ongoing NIHR HTA-funded trial ('Best Emollient for Eczema', www.bristol.ac.uk/ bee-study), due to report in late 2020.

Matthew Ridd,

Senior Lecturer, Centre for Academic Primary Care, University of Bristol, Bristol. Email: M.Riddabristol.ac.uk

\section{REFERENCE}

1. Emollients and moisturisers for eczema. http:// www.cochrane.org/CD012119/SKIN_emollientsand-moisturisers-eczema (accessed 8 Mar 2018).

DOI: https://doi.org/10.3399/bjgp18X695717 